DOI: $10.17805 /$ zpu.2015.2.16

\title{
Начало исторической науки в Европе: тезаурус Августа Людвига Шлёцера
}

\author{
Ю. А. ВАСИЛЬЕВ \\ (МОСКОВСКИЙ ГУМАНИТАРНЫЙ УНИВЕРСИТЕТ)
}

Немецкий историк Август Людвиг Шлёцер (1735-1809) до сих пор, как правило, ассоциируется лишь с образом непримиримого противника направления антинорманистов в России и лично российского ученого М. В. Ломоносова. Подобный взгляд представляется автору данной статьи ограниченным и упрощенным. Шлёцер является одним из наиболее видных немецких ученых, лидером гёттингенской школы историков в Германии в конце XVIII - начале XIX в. Именно ему и его школе принадлежит приоритет введения в научный оборот и разработки понятий «всемирная история», «всеобщая история», "история человечества», «вспомогательные исторические дисциплины». Хронологически раньше других школ в Европе Шлёцер и его коллеги начали возведение истории в ранг науки.

В статье использован новаторский методологический прием, связанный с тезаурусным анализом в гуманитарном знании, который активно используется в научной школе Московского гуманитарного университета (Вал. А. Луков, Вл. А. Луков и др.). Обоснована возможность применения тезаурусного подхода как субъектно ориентированного исследовательского инструментария в отношении интерпретации и понимания периода конституционализации исторической науки в Европе, характеристикой которого являлась неполнота знаниевых систем. Автор публикации акцентирует внимание на тезаурусных константах и концептах Шлёцера.

В статье отмечается явление своеобразной двойной рецепции идей в период службы и пребывания Шлёцера в России в 1761-1767 гг. С одной стороны, Шлёцер разработал конструктивные приемы исторической критики исторических текстов, которые нашли широкое применение в русской исторической школе в XIX в. С другой, он находился под сильным влиянием русской историографии, особенно обобщающих сочинений по русской истории М. В. Ломоносова и В. Н. Татищева. Примечательна, по оценке автора статьи, созвучная оценка Шлёцера и Ломоносова в отношении важных явлений русской истории (роль славян в мировой истории, образ исторического процесса в качестве великой реки, понимание истории как многоуровневой и многофакторной системы и др.).

Предложенные Шлёцером исследовательские подходы (синтетический, системный, синхронный) нашли развитие в наследии русской исторической школы.

Ключевые слова: история, историческая наука, Европа, А. Л. Шлёцер, тезаурус, тезаурусный подход, гёттингенская школа историков, рецепция, русская историческая школа.

\section{BВЕАЕНИЕ}

$\mathrm{B}$ качестве периода институционализации исторической науки в Европе следует определить конец XVIII - начало XIX в. В европейском историописании до этого времени история рассматривалась как часть художественной прозы. Оформление научной историографии началось сначала в Германии: гёттингенский, гейдельбергский, берлинский университетские центры гуманитарных исследований предприняли усилия для выделения истории в самостоятельную науку. С этой поры историческая наука заменила поэтическое искусство и стала иметь большое значение для культуры и жизни немецкой нации (Автобиография Гервинуса, 1895: 157). Фридрих Шлоссер (1776-1861), Фридрих Вилькен (1777-1840) явились основателями школы исследователей Средних веков; Бартольд Нибур (1776-1831) заложил основы для развития критической школы.

Однако представляется, что особый вклад в становление европейской традиции исторической науки внес Август Аюдвиг Шлёцер (Schlözer) (1735-1809). Обучаясь 
в одном из лучших в Германии университетов - Гёттингенском, - он получил основания научного знания от своих учителей: И. С. Пюттера в области теории и истории государства и права, Г. Ахенваля - в статистике как науке, но особенно И. А. Михаэлиса - в новой школе исторической критики. Пребывание и служба в Петербургской академии наук в 1761-1767 гг. стали для него полигоном в реализации собственных амбициозных исследовательских планов. После возвращения на родину Шлёцер с 1769 г. являлся профессором Гёттингенского университета. В 1770-е годы он стал лидером гёттингенской школы историков.

\section{A. А. ШАЁЦЕР В ФОКУСЕ ТЕЗАУРУСА}

Изучение роли А. $\Lambda$. Шлёцера в становлении истории как науки, как представляется, возможно провести в контексте тезаурусного анализа. Если сегодня тезаурусный подход направлен на стирание дисциплинарных рамок отдельных гуманитарных наук, то в применении к концу XVIII в. он мог олицетворять другую ситуацию - отсутствие оформленной гуманитарной науки и ее деления на отдельные самостоятельные дисциплины. По выражению Ф. Анкерсмита, сегодня «добрые старые времена единства науки, видимо <...> снова возвращаются» (Анкерсмит, 2007: 71).

Тезаурус определяется как субъектно организованное гуманитарное знание, которое позволяет постигать окружающий мир. Причем свод освоенных социальным субъектом знаний имеет существенное значение для него в качестве средства ориентации в окружающем мире. Придание особого значения социальной и культурной субъектности основано на констатации неполноты знаниевых систем, в то же время на признании полноты и достаточности для реализации ориентационной функции. Основа систематизации знаний в тезаурусе - конструкция свое - чужое - чуждое, которая отличается от объективных знаниевых систем (Ауков, 2014: 127).

Неполнота знаниевых систем являлась характерной чертой интеллектуальной мысли в Европе до конца XVIII в. Ао этого времени в Германии не было серьезных исследований о Средних веках, а по древней истории имелись лишь слабые латинские компиляции. Аналогичная ситуация сложилась и во всей Европе: историческая наука находилась в зачаточном состоянии. Примечательно, что немецкие историки вообще не воспринимали лидера французской историографии Вольтера в качестве квалифицированного историка. Они считали, что Вольтер «оказывается вовсе неспособным перенестись в чужеземные условия» (Принципы историографии Гервинуса, 1895: 314).

Характерной чертой всех без исключения национальных историй европейских стран являлась синкретичность повествований с мифами. История народов приукрашивалась в сказаниях, становилась выражением тех идеалов, к которым устремлен дух народа. Иоганн Аройзен называл историю областью нравственных наук. По его оценке, «греки нарисовали себе чудесную, гармоничную картину своего прошлого с тем, что от нее сохранилось действительно подлинного, она, к великому сожалению, совпадает мало» (Аройзен, 2004а: 446). В Античности господствовало представление, что история относится к области риторики. Римская история также воспринималась частью риторики, художественной литературы. В XVIII в. это представление вновь возродилось в тезисе, что история является одновременно и наукой, и искусством.

В контексте современных трактовок измерения истории можно констатировать, что в истории любой цивилизации существует неотъемлемая часть мифологизированного прошлого, которое она не может историзировать (т. е. сделать фактом истории), но которое в значительной мере определяет ее идентичность - иногда даже в боль- 
шей степени, чем историзированное прошлое. В общественном сознании на определенных этапах развития проявляется стремление историзировать мифы своей истории, однако нередко вместо историзации мифов происходит историзирование только способа обращения с существующими мифами. В данном проявлении историография функционирует в качестве заместителя самой истории. В подобной репрезентации состоит суть и назначение сочинений по истории. Знание никогда не сможет заменить реалий прошлого. Поэтому «холодное» сердце цивилизации навсегда останется вне досягаемости историка. Мифологическое прошлое нельзя историзировать само по себе, поскольку это диссочиированное прошлое, недоступное даже для самых основательных попыток историзации, находящееся за пределами исторического времени. Оно пользуется высочайшим почетом: это есть историческое возвышенное цивилизации (Анкерсмит, 2007: 501, 503).

\section{ШАЁЦЕР И РОССИЯ: ФЕНОМЕН АВОЙНОЙ РЕЦЕПЦИИ}

В период пребывания Шлёцера в России отмечается своеобразная двойная рещеnиия. С одной стороны, по оценке В. О. Ключевского, «начиная с Карамзина и кончая Соловьевым, все русские историографы XIX в. смотрели на Шлёцера как на первоучителя, родоначальника своей науки и руководились его приемами» (Ключевский, 1989: 230). Шлёцер оказал русской историографии «важные методологические услуги»в области разработки исторической критики. В «самородную русскую критику» он внес конструктивные исследовательские правила, «если не общепризнанные, то во всяком случае более надежные и полезные» (там же: 233). Шлёцер высказал немало приемов изучения и исправления текста, сделал много поправок в летописном тексте. Тезаурусный анализ проявляется в отношении конструктов Шлёцера как субъектно ориентированного исследовательского инструментария. Идеи Шлёцера сформулированы как «низшая критика» - анализ исторического источника и «высшая критика»исследование степени достоверности его сведений. Они отличались новизной и конструктивностью для своего времени в области изучения русской истории. Однако для многих коллег Шлёцера в России, включая иностранцев, историческая критика воспринималась как нечто чужое, неосвоенное, отмеченное пугающей новизной. Тем не менее предложенные Шлёцером приемы со временем осваивались и находили признание, т. е. становились своими. В то же время осознавалось, что традиционное $c$ вое нередко оказывается непродуктивным.

Одновременно происходила обратная рещепиия: Шлёцер находился под сильным влиянием русской историографии второй половины XVIII в. (там же: 221). В этой связи для становления его как ученого историка следует подчеркнуть значимость обобщающих сочинений российских исследователей М. В. Аомоносова и В. Н. Татищева. Чтобы оценить их интеллектуальную деятельность в условиях, когда еще не существовало национальных научных школ в области истории в европейских странах, важно принять в расчет следующий критерий: с одной стороны, было наследие, доставшееся от предшественников (его практически не было), с другой - преимущества, которые получили их преемники и последователи в виде основания для дальнейшей разработки древней истории. Именно таким стартовым интеллектуальным багажом явилось историческое наследие российских мыслителей, стоявших у истоков русской исторической школы. Шлёцер не создал и не мог создать обобщающего труда, посвященного истории России. По Ключевскому, он не был достаточно подготовлен к научному изучению истории России. Но он имел превосходную подготовку к историко-критической работе. Все его внимание сосредоточилось на критическом изучении русской 
истории (там же: 231). Исследовательский талант Шлёцера раскрылся в применении сравнительного анализа летописных известий и в опыте критического сравнения текстов, а также в рационалистических приемах реконструкции первоначального текста. Намеченное Шлёцером направление исследовательской деятельности нашло продолжение и развитие в российской исторической науке (Свердлов, 2011: 832-833). В конце научной деятельности в Германии (1802-1809) Шлёцер обобщил свои исследования древнерусского летописания и истории в пятитомном труде - знаменитом «Несторе» (Несторъ. Russische Annalen ..., 1802-1809). За данный труд он был возведен Aлександром I в дворянское достоинство и награжден российским орденом Владимира IV степени.

В течение более чем Авух с половиной столетий бесконечного противостояния «норманистов» и «антинорманистов» в России акцентировалось внимание на антинаучности и негативной деятельности «немцев» по принципу разделения двух непримиримых лагерей на свой и чужой. Однако за внешней непримиримостью А. $\Lambda$. Шлёцера и М. В. Цомоносова скрывается различие исследовательских подходов: историческая критика Шлёцера с ее позитивистским вектором не совпадала с историософской парадигмой Аомоносова (Васильев, 2014; Васильев, Васильева, 2014). Однако с позиции тезаурусного подхода у двух различных инструментариев есть нечто общее: и в одном случае, и в другом проявляет свое действие субъективность - в анализ исторической действительности привносится оценочный момент. За это как Шлёцер, так и Аомоносов подвергались критике, особенно с позиции историзма XIX в. В отличие от прошлого сегодня, напротив, при написании истории историку рекомендуется, по словам Ф. Анкерсмита, «использовать всю свою личность». Анкерсмит пишет: «То, как историк относится к собственному времени, каковы его внутренние чувства и переживания, какие факты оказались решающими в его собственной жизни - все эти вещи должны быть не окутаны недоверием и страхом как угроза так называемой исторической субъективности, но ценимы как важнейшее снаряжение историка, пытающегося проникнуть в тайны прошлого. Конечно, эти личные переживания не могут и не должны использоваться в качестве аргумента при изложении историком прошлого - мы хотим читать о прошлом, а не об историках, - но они абсолютно необходимы для того, чтобы он был открыт опыту прошлого. Что, в свой черед, помогает перебросить мост в прошлое и историку, и его читателям» (Анкерсмит, 2007: 267).

\section{ПОИСК НАУЧНОГО МЕТОАА В ИСТОРИИ}

В числе первых гёттингенская школа историков в конце XVIII в. от Иоганна Кристофа Гаттерера (1727-1799) до Августа Аюдвига Шлёцера разработала систематику наук и вспомогательных дисциплин, попыталась сделать систематический обзор истории и развить ее научный метод. Исследовательская концепция Шлёцера изложена в его работе «Представление всеобщей истории» (1772). Благодаря гёттингенской школе в научный обиход были введены понятия всемирная история, всеобщая история, история человечества, исторические вспомогательные науки. Однако позднее исследовательский метод гёттингенской школы И. Аройзен оценивал лишь в качестве «техники исторической работы» (Аройзен, 2004b: 577). Воспринятое представителями этой школы понятие Вольтера «философия истории» (philosopbie de l'bistoire) pacсматривалось как приглашение к изучению истории, адресованное философам, «взять на себя обоснование не только исторического процесса познания, которое в высшей степени заслуживало бы благодарности, но и обоснование связей исторически полученных результатов, пока затем в одной системе не был сконструирован об- 
щий исторический труд всего рода человеческого как самодвижущаяся идея» (там же).

А. $\Lambda$. Шлёцер поставил конкретный вопрос: что такое историческая наука? (Шлёцер, 1809: 42-43). В его исторической концепции научное представление должно включать, во-первых, понятие о систематической истории мира, во-вторых, синхронистическое расположение всемирной истории по периодам, в-третьих, синтетическое расположение всемирной истории (хроно-техно-гео-этнографическое).

Предмет систематической истории мира, по Шлёцеру, - перемены человеческого рода. Содержание всемирной истории составляют великие изменения, происходившие в истории человечества. Всемирная история характеризуется двойственным определением: с одной стороны, это сумма всех особенных историй; с другой - предстает в качестве системы, в которой человеческий мир является целостной единицей. Всеобщее обозрение претворяет сумму в систему, приводит все государства к единице, т. е. к роду человеческому, оценивает все народы по их отношению к великим переменам мира. Сумма государств не является системой всемирной истории, в ней нет представления о целом. Всемирная история произрастает из частных историй, но они составляют целое (там же: 13-14, 18, 33). По определению Шлёцера, «политическая связь есть мать человечества» (там же: 15$)$.

Некоторые части всемирной истории могут рассматриваться отдельно. Всеобщая история показывает, каким образом появился мир в целом и в частях, чем он был ранее и чем стал сегодня, как соединяется прошедший мир с нынешним, предлагается их взаимное отношение. Каждый народ имеет иастную историю. Всеобщая история совокупность особенных историй в отношении к другим частям и к целому. Последнее придает форму всеобщей истории - выбор и образ соединения перемен. Всеобщая история объединяет все части света и все времена, соединяет во всех землях все народы в единый человеческий мир. Целостность истории проявляется в том, что в любой частной истории содержатся основания из всеобщей истории. Собрание всех историй, приведенное в систему, производит всеобщую европейскую историю. Систематическая история предполагает философское осмысление ряда проблем: как произошла Европа, каким образом она достигла высокой степени развития, как отдельные страны возвысились на основе просвещения, продвижения нравов и роста могущества перед другими (там же: 2-4, 13, 30).

Рассмотрение немецкой истории как частной через призму всеобщей истории как системы, по схеме Шлёцера, должно способствовать приобретению сведений о всеобщей истории. Изучение немецкой истории позволит ответить на вопрос: как произошла Германия? В фокусе исследования одновременно должны находиться Европа и род человеческий, Германия и германский народ (там же: 2-3).

В истории народов, включенных в классификацию Шлёцера, отразились великие происшествия мира - значимые события или явления всеобщей истории. Отмечая важность для истории только действительно великих деяний, включая их причины (образ правления, законодательство, политика, просвещение нравов, законы и науки, уровень земледелия, торговли, мануфактуры и др.), Шлёцер подчеркивал, что все это необходимо понять посредством многоуровневой и многофакторной системь. В этой связи выдвигались строгие требования к науке. Признавалось мнение, что историк только на расстоянии времени может правильно судить о предмете изучения прошлого. Отвергались спекулятивные умствования, живописания, беседы и рассуждения - основой научного знания признавались только выбранные и классифицированные происшествия (см. там же: 21-22, 77). В данном подходе явно просматривается 
взгляд, предварявший будущие установки в духе позитивизма. По Шлёцеру, «читатель сам о них рассуждение придумать должен» (там же: 24).

Синхронистический подход к истории предполагает расположение истории по периодам. Но для этого ставятся определенные условия. Всемирная история должна освещать все главные перемены мира. Исторические события (в терминологии Шлёцера - происшествия) предполагают следующие тезаурусные константы: память (запомнить и сохранить), Воображение (рассмотрение их в хронологической последовательности и во всех связях), разум (рассмотрение всеобщего как целого, отличие системы от суммы). Именно для этого необходимо деление истории на әпохи и периоды (там же: 37,57$)$. Однако, несмотря на выдвинутые строгие требования к научному знанию, состояние исторического знания 1770-х годов не могло позволить Шлёцеру подняться выше мифологического характера периодизации истории.

Разделение исторического процесса на эпохи, периоды неизбежно приводит к потере общей красоты картины восприятия. Но научный метод не должен прерывать союза явлений (событий) и союза времен - в этом суть синхронистического (единовременного) метода изучения истории. Аанный метод всеобщей истории определяет способ объединения отдельных частей и периодов. Он заключается во всеобщем обозрении целого, связи происшествий - соединении причины и следствия, взаимных отношений между событиями (там же: 43-45, 50).

В контексте синхронистического подхода методологическое различие системы от суммы отразилось в оценке истории отдельных народов. По Шлёцеру, в истории выбирается из целого множество сумм - те народы, которые являлись ведущими. В этот перечень определялись слаљяне наряду с франками, норманнами, монголами, турками, китайцами, аравийцами и другими этносами. Славяне рассматривались как великий народ, который появляется в истории, как утверждал Шлёцер, не ранее VI в. Аля обоснования этого утверждения приводилось довольно сомнительное свидетельство Иордана о том, что король остготов Германарих называл славян среди побежденных им народов. Шлёцер подчеркивал, что ни в одной летописи нет свидетельств о переселении многочисленных славянских народов в Европу с Востока, а язык славян - европейский (там же: 103, 191). В отношении монголов опровергалось определение их как татар в германской, польской и российской историях (там же: 225).

Критерием выбора значимых народов определялась не слава их деяний, не событийная насыщенность их историй, а влияние на целое, на основные регионы мира. Шлёцеровская классификация народов имела троякое деление. Первую группу составляли победоносные народы: персы, татары и монголы и др. Во вторую группу определялись Важные народы: египтяне, финикийцы, евреи, греки и др. В третью группу включались главные народы: ассирийцы, македонцы, испанцы, британцы. По оценке Шлёцера, россияне входят именно в эту группу главных народов (там же: 19-20, 23, 100). А вот укры (пограничные венды), по Шлёцеру, как и ряд других славянских племен (в частности, в Бранденбургских землях), были практически уничтожены (там же: 193). Следует подчеркнуть, что и М. В. Аомоносов отстаивал самобытность славян, а историю России рассматривал прежде всего как историю российского народа. Однако в отличие от Шлёцера хронологически для Аомоносова было неоспоримо происхождение многочисленных славянских народов в российских пределах прежде Рождества Христова, а также то, что историческая роль славян на этих землях проявилась уже в первые века нашей эры (Аомоносов, 1986: 52-55).

Аля рассмотрения великих событий необходим двойственный подход к изучению: синхронистический и синтетический. Последний свидетельствует о том, что история 
включает происшествия из всех областей жизни, содержащие в себе основания важных перемен рода человеческого: историю государств, законов, торговли, художеств, учености, изобретений и пр. Критерий значимости происшествий для всего человечества должен определяться влиянием истории как науки на психологию, политику, физику и другие науки. Синтетический подход, по Шлёцеру, олицетворялся со следующим образом исторического процесса: государства в своей истории разделялись, как некие великие реки, на многие рукава, но их история продолжалась в новом качестве (Шлёцер, 1809: 28-29, 46, 56). В этой связи показательна также ломоносовская ассоциация исторического процесса как временного потока человеческого бытия с образом течения великой реки, «которая, от источников своих по широким полям распростираясь, иногда в малые потоки разделяется и между многими островами теряет глубину и стремление; но, паки соединясь в одни береги, вящую быстрину и великость приобретает; потом присовокупив в себя иные великие от сторон реки, чем далее про-

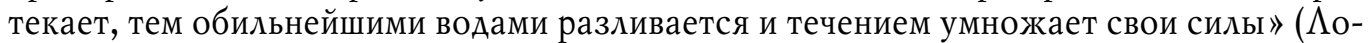
моносов, 1986: 48). Примечательно, что синтетический подход во второй половине XIX в. стал методологическим основанием исторических концепций выдающихся представителей русской исторической школы - В. О. Ключевского и Н. И. Кареева. Сегодня синтетический подход в историописании, ориентированный на возвращение к человеку как предмету исторических исследований, поддерживают ведущие западные теоретики истории: Йорн Рюзен и Георг Иггерс в Германии, Франклин Анкерсмит в Нидерландах, Питер Берк в Великобритании, Аайонел Госсмен, Алан Мегилл в США и ар.

\section{ЗАКАЮЧЕНИЕ}

В основе тезауруса Шлёцера - репрезентация картины мира прошлого его исследователем, которая обретает свойства объективной действительности. В подобном восприятии тезаурусный подход выступает инструментарием гуманитарного знания, направленного на комплексное субъективно ориентированное представление о мире и человеке. Методология тезауруса Шлёцера может определяться как стратегия понимания.

\section{СПИСОК АИТЕРАТУРЫ}

Автобиография Гервинуса (1895)/ Г. Г. Гервинус; пер. Э. Циммермана. М. : Изд. К. Т. Солдатенкова. 359 с.

Анкерсмит, Ф. Р. (2007) Возвышенный исторический опыт. М. : Европа. 612 с.

Васильев, Ю. А. (2014) Идеи М. В. Аомоносова в русской исторической школе // Знание. Понимание. Умение. № 2. С. 141-148.

Васильев, Ю. А., Васильева, М. Ю. (2014) Влияние идей Христиана Вольфа на мировоззрение М. В. Аомоносова // Власть. № 3. С. 121-125.

Аройзен, И. Г. (2004а) Речь, произнесенная при вступлении в Берлинскую академию наук // Аройзен, И. Г. Историка. Аекции об энциклопедии и методологии истории. СПб. : Владимир Ааль ; Фонд «Университет». 582 с. С. 574-580.

Аройзен, И. Г. (2004b) Энциклопедия и методология истории // Аройзен, И. Г. Историка. Аекции об энциклопедии и методологии истории. СПб. : Владимир Ааль ; Фонд «Университет». 582 c. C. $39-448$.

Ключевский, В. О. (1989) Соч. : в 9 т. / под ред. В. А. Янина. М. : Мысль. Т. 7: Специальные курсы (продолжение). 508 с.

Иомоносов, М. В. (1986) Избр. произведения : в 2 т. М. : Наука. Т. 2. История. Филология. Поэзия. 496 с. 
Ауков, В. А. (2014) Тезаурусный анализ в гуманитарном знании: итоги проекта // Знание. Понимание. Умение. № 4. С. 125-136.

Принципы историографии Гервинуса. 1837 г. Приложение II (1895)// Автобиография Гервинуса / Г. Г. Гервинус ; пер. Э. Циммермана. М. : Изд. К. Т. Солдатенкова. 359 с. С. 295-342.

Свердлов, М. Б. (2011) М. В. Аомоносов и становление исторической науки в России. СПб. : Нестор-История. 916 с.

Шлёцер, А. А. (1809) Представление всеобщей истории. СПб. : Тип. при Святейшем Правительствующем Синоде. 227 с.

Несторъ. Russische Annalen in ihrer Slavonischen Grund Sprache (1802-1809) : in 5 t. / A. L. von Schlözer. Göttingen : Heinrich Dieterich, 1802-1805, T. 1-4 ; Vandenhoek und Ruprecht, 1809, T. 5.

Аата поступления: 10.03.2015 г.

\section{THE BEGINNING OF HISTORY AS A DISCIPLINE IN EUROPE: THESAURUS OF AUGUST LUDWIG VON SCHL?ZER \\ YU. A. VASILIEV \\ (MOSCOW UNIVERSITY FOR THE HUMANITIES)}

August Ludwig von Schl?zer (1735-1809) is still most often remembered as the inveterate opponent of Russian anti-Normanists and specifically and personally, of Mikhail V. Lomonosov. We consider this view too limited and simplified. Schl?zer has the right to be recognized as one of the most prominent German scholars and the leader of the G?ttingen school of history at the end of the $18^{\text {th }}$ and early $19^{\text {th }}$ century. It was he and his followers who first developed and introduced the concepts of "world history", "general history", "history of mankind", "auxiliary historical disciplines". Schlözer and his colleagues were the first to begin elevating history to the rank of a separate field of study.

The article employs an innovative approach borrowed from thesaurus analysis in the humanities, now actively used by research groups and schools at Moscow University for the Humanities (Valery A. Lukov, Vladimir A. Lukov and others). We prove that the thesaurus approach can act as a subjectoriented research tool in interpreting and understanding of the period of constitutionalization of history as a discipline. The incompleteness of knowledge systems was a feature typical for this period. We focus specifically on Schlözer's concepts and thesaurus constants.

The article also traces the curious phenomenon of "double reception" of Schlözer's ideas during his stay in Russia in 1761-1767. On the one hand, Schl?zer developed constructive methods of historical criticism of historical texts, which were widely used by the Russian historical school later on, in the 19th century. On the other, Schlözer was himself heavily influenced by Russian historiography, especially by systematical works on Russian history by Mikhail V. Lomonosov and Vasily N. Tatishchev. It is worth mentioning that Schlözer and Lomonosov had a similar take on some important events and concepts (the role of the Slavs in world history, the image of the historical process as a great river, the understanding of history as a multi-level and multi-factor system, etc.).

The synthetic, systemic and synchronous approaches to research proposed by Schl?zer found their new development in the heritage of Russian historical school.

Keywords: history, discipline of history, Europe, A. L. von Schlözer, thesaurus, thesaurus approach, Göttingen school of history, reception, Russian historical school.

\section{REFERENCES}

Avtobiografiia Gervinusa [The Autobiography of Gervinus] (1895) / G. G. Gervinus ; transl. by E. Tsimmerman. Moscow, K. T. Soldatenkov's Publ. 359 p. (In Russ.).

Ankersmit, F. R. (2007) Vozvyshennyi istoricheskii opyt [Sublime historical experience]. Moscow, Evropa Publ. 612 p. (In Russ.).

Vasiliev, Yu. A. (2014) Idei M. V. Lomonosova v russkoi istoricheskoi shkole [The ideas of M. V. Lomonosov in the Russian historical school]. Znanie. Ponimanie. Umenie, no. 2, pp. 141-148. (In Russ.). 
Vasiliev, Yu. A. and Vasilieva, M. Yu. (2014) Vliianie idei Khristiana Vol'fa na mirovozzrenie M. V. Lomonosova [The influence of Christian Wolff's ideas on M. V. Lomonosov's views]. Vlast', no. 3, pp. 121-125. (In Russ.).

Droysen, J. G. (2004a) Rech', proiznesennaia pri vstuplenii v Berlinskuiu Akademiiu nauk [Inaugural speech at the Berlin Academy of Sciences]. In: Droysen, J. G. Istorika. Lektsii ob entsiklopedii $i$ metodologii istorii [Historica. Lectures on the encyclopedia and methodology of history]. St. Petersburg, Vladimir Dal' Publ. ; “Universitet” Foundation. 582 p. Pp. 574-580. (In Russ.).

Droysen, J. G. (2004b) Entsiklopediia i metodologiia istorii [Encyclopedia and methodology of history]. In: Droysen, J. G. Istorika. Lektsii ob entsiklopedii i metodologii istorii [Historica. Lectures on the encyclopedia and methodology of history]. St. Petersburg, Vladimir Dal' Publ. ; "Universitet" Foundation. 582 p. Pp. 39-448. (In Russ.).

Klyuchevsky, V. O. (1989) Socbineniia [Works] : in 9 vols. / ed. by V. L. Yanin. Moscow, Mysl' Publ. Vol. VII: Spetsial' nye kursy (prodolzhenie) [Special courses (continuation)]. 508 p. (In Russ.).

Lomonosov, M. V. (1986) Izbrannye proizvedeniia [Selected works] : in 2 vols. Moscow, Nauka Publ. Vol. 2. Istoriia. Filologiia. Poeziia [History. Philology. Poetry]. 496 p. (In Russ.).

Lukov, V. A. (2014) Tezaurusnyi analiz v gumanitarnom znanii: itogi proekta [Thesaurus analysis in humanitarian knowledge: Project outcomes]. Znanie. Ponimanie. Umenie, no. 4, pp. 125-136. (In Russ.).

Printsipy istoriografii Gervinusa. 1837 g. Prilozhenie II [Principles of historiography according to Gervinus. 1837. Appendix II] (1895). In: Avtobiografiia Gervinusa [The autobiography of Gervinus]/ G. G. Gervinus ; transl. by E. Tsimmerman. Moscow, K. T. Soldatenkov's Publ. 359 p. Pp. 295-342. (In Russ.).

Sverdlov, M. B. (2011) M. V. Lomonosov $i$ stanovlenie istoricheskoi nauki v Rossii [M. V. Lomonosov and the development of historical studies in Russia]. St. Petersburg, Nestor-Istoria Publ. 916 p. (In Russ.).

Schlözer, A. L. (1809) Predstavlenie vseobshchei istorii [A presentation of world history]. St. Petersburg, Printing House of the Most Holy Governing Synod. 227 p. (In Russ.).

Nestor. Russische Annalen in ibrer Slavonischen GrundSprache (1802-1809) : in 5 t. / A. L. von Schlözer. Göttingen : Heinrich Dieterich, 1802-1805, T. 1-4 ; Vandenhoek und Ruprecht, 1809, T. 5.

Submission date: 10.03.2015.

Васильев Юрий Альбертович - доктор исторических наук, профессор, профессор кафедры истории Московского гуманитарного университета. Адрес: 111395 , Россия, г. Москва, ул. Юности, А. 5, корп. 3. Тел.: +7 (499) 374-55-81. Эл. адреc: historymosgy@mail.ru

Vasiliev Yuriy Albertovich, Doctor of History, Professor, Department of History, Moscow University for the Humanities. Postal address: Bldg. 3, 5 Yunosti St., 111395 Moscow, Russian Federation. Tel.: +7 (499) 374-55-81. E-mail: historymosgy@mail.ru 